\title{
A study on risk factors and clinical presentation of ectopic pregnancy
}

\author{
Nethra H S, Praneetha K, Sreelatha S, Seema Shyam Bhairi \\ Correspondence: Dr Sreelatha S, Professor, Department of Obstetrics and Gynaecology, \\ ESIMC, PGIMSR, Rajaji Nagar, Bangalore , India; Email - dr.sreelatha2011@gmail.com \\ Distributed under Creative Commons Attribution-Share Alike 4.0 International.
}

\begin{abstract}
$\underline{\text { ABSTRACT }}$
Objectives: The present study was designed to study the risk factors of ectopic pregnancy and their clinical presentation. Material and methods: It was a retrospective study with 100 cases of ectopic pregnancy conducted in the Department of Obstetrics and Gynecology, ESIC MC PGIMSR, Rajajinagar, Banglore for a period of 2 years were included. Detailed history suggestive of risk factors for ectopic pregnancy, menstrual and obstetric history was taken. Results: A total of 7200 pregnancies were confirmed during the study period, of which 100 cases of ectopic pregnancies were diagnosed, giving an incidence of $1.38 \%$. Sixty three percent were in the age group of 21-30 years. Seventy six percent of women were multigravidae. Forty eight percent of the patients had identifiable risk factors, of which past history of pelvic inflammatory disease in $28 \%$, history of previous abortion in 16\%, infertility in $10 \%$, history of previous ectopic pregnancy in $14 \%$, history of previous caesarian section in $18 \%$ and tubectomy in $14 \%$ were noted. Ninety six percent had amenorrhea, followed by pain abdomen in $88 \%$, bleeding per vagina in $78 \%$, fainting and syncopal attack in $16 \%$ of the patients. Pallor in $56 \%$ of the cases, $10 \%$ presented with shock. Conclusion: The early diagnosis of an ectopic pregnancy is one of the greatest challenges for a physician. It requires a high index of suspicion in case of clinical presentation of pain abdomen, bleeding per vagina with amenorrhoea. The importance of an early diagnosis lies in the fact that the patient can be offered a conservative line of management which can definitely have a beneficial effect on her future fertility.
\end{abstract}

Keywords: Amenorrhea, hemoperitoneum, ruptured ectopic, shock, vaginal bleeding.

Ectopic pregnancy is defined as extrauterine pregnancy in which the fertilized ovum implants at an aberrant site which is inconducive to its growth and development ${ }^{1}$. Ectopic pregnancy is assuming greater importance because of its increasing incidence and its impact on women fertility ${ }^{2,3}$. Ectopic pregnancy remains the leading cause of maternal deaths in early pregnancy ${ }^{4}$. Although women with ectopic pregnancy frequently have no identifiable risk factors, a prospective case-controlled study has shown that increased awareness of ectopic pregnancy and a knowledge of the associated risk factors helps identify women at higher risk in order to facilitate early and more accurate diagnosis. Most risk factors are associated with risks of prior damage to the Fallopian tube. These factors include any previous pelvic or abdominal surgery, and pelvic infection. Chlamydia trachomatis has been linked to $30-50 \%$ of all ectopic pregnancies. Patients with an ectopic pregnancy

Received: 4 th July 2017. Accepted: 26 th September 2017.

Nethra H S, Praneetha K, Sreelatha S, Bhairi SS. A study on risk factors and clinical presentation of ectopic pregnancy. The New Indian Journal of OBGYN. 2018; 4(2): 146 - 49. 
commonly present with pain and vaginal bleeding between 6 and 10 weeks' gestation. The early diagnosis and treatment of this condition over the past two decades has allowed a definitive medical management of unruptured ectopic pregnancies even before there were clinical symptoms in these high risk women ${ }^{5,6}$. The current trend is a conservative way of management of these pregnancies be it chemotherapeutic agents or conservative surgical approaches, the ultimate goal is tubal conservative procedures rather than radical surgeries ${ }^{7,8}$. The aim of the present study was to see the risk factors of ectopic pregnancy and their clinical presentation.

\section{Methods}

This retrospective study was done at ESIC MC PGIMSR, Rajajinagar, Banglore from January 2015 to December 2016. The case sheets of the patients with ectopic pregnancy were traced through the labour ward registers and operation theatre registers and medical record department. Information regarding the total number of deliveries in the study period, clinical symptoms and signs, diagnostic tools used, treatment, risk factors for the ectopic pregnancy as well as associated morbidity and mortality were obtained. Data were analyzed in number and percentage.

\section{Results}

During the study period of two years, there were a total of 7200 deliveries in our hospital and 100 cases of ectopic pregnancies were operated giving the incidence of

Table 1: Showing age distribution, gravidity, socioeconomic status

\begin{tabular}{lll}
\hline Categories & & Percentage \\
\hline Age in years & $<19$ & 4 \\
& $20-25$ & 41 \\
& $26-30$ & 22 \\
& $31-35$ & 25 \\
Gravidity & $>35$ & 8 \\
& Primigravida & 24 \\
Socioeconomic & Multigravida & 76 \\
status & Lower & 74 \\
\hline
\end{tabular}

ectopic pregnancies of 1.38/1000 deliveries. A majority of the patients $(63 \%)$ belonged to the age group of 21-30 years. Twenty four percent were primigravidae and $76 \%$ were multigravidae. In our study group, majority of women with ectopic pregnancy (74\%) belonged to low socio economic status and $26 \%$ belonged to high socioeconomic status (Table 1).

Risk factors were previous history of tubectomy (14\%), spontaneous and induced abortion (16\%), 10\% had

\section{Table 2: Showing risk factors}

\begin{tabular}{ll}
\hline Risk Factors & Percentage \\
\hline Previous history of ectopic & 14 \\
Previous history of tubectomy & 14 \\
Previous history of LSCS & 18 \\
Previous abortion & 16 \\
PID & 28 \\
Infertility & 10 \\
\hline
\end{tabular}

a history of infertility. A history of previous ectopic in (14\%) where partial salpingectomy was done. Eighteen percent had a history of previous caesarian section and history of pelvic inflammatory disease (PID) was found in $28 \%$ of the case (Table 2).

Ninety six percent had amenorrhea, followed by pain abdomen in $88 \%$, bleeding per vagina in $78 \%$, fainting and syncopal attack in $16 \%$ of the patients. Pallor in $56 \%$ of the cases, $10 \%$ presented with shock was noted. Percentage of haemoglobin was $<7 \mathrm{gm} \%$ in $28 \%$ observed. Sixty three patients were ruptured ectopic were recorded. Twenty two were unruptured ectopics and 15 were tubal abortions.

\section{Discussion}

A total of 100 cases of ectopic pregnancies were studied. A total of 7200 pregnancies were confirmed during the study period, out of which 100 cases were diagnosed as ectopic pregnancies giving an incidence of $1.38 \%$. The present study is correlating with the study done by Musa, et al. ${ }^{9}(1.74 \%)$.

Rising incidence of sexually transmitted infections, induced abortions, social and life style changes, late child bearing in career women, assisted reproductive technologies and advances in diagnostic techniques are the contributing factors for rising incidence of ectopic pregnancy globally.

Majority of women (63\%) in our study group belonged to the age group of 21-30 years, which is close to the studies done by Samiya Mufti et al. ${ }^{10}$ (75.4\%), Panchal D et al. ${ }^{11}(71.66 \%)$ and Rashmi A Gaddagi et al. ${ }^{12}(70.2 \%)$. Most of the women in India marry at an early age and 
completes their family at an early age. This age corresponds to the age of peak sexual activity and reproduction.

In our study group, most of the women belonged to low socioeconomic status $(74 \%)$ which is close to the study done by Poonam et al. ${ }^{13}(69.3 \%)$. Women belonging to low socioeconomic status will have poor personal hygiene and lack of immunity, predisposing them to pelvic inflammatory diseases including tuberculosis.

In the present study group, majority of women with ectopic pregnancy were multigravidae $(76 \%)$. This correlates with the studies done by Shraddha Shetty K et al. ${ }^{14}$ (83.9\%), Panchal D et al. ${ }^{11}(81.66 \%)$ and Poonam et al. ${ }^{13}(83.6 \%)$. The higher incidence in multigravidae is probably due to previous miscarriages and infections resulting in tubal damage.

In the present study group, history of PID was present in $28 \%$ of the cases with ectopic pregnancy. This is correlating with the study done by Bhavna, et al. ${ }^{15}$ 22.7\% of the cases with ectopic pregnancy.

Endosalpingitis damages the mucosa and may entrap the migrating embryo, leading to ectopic implantation. Exosalpingitis give rise to peritubal adhesions, impairing peristaltic movements, giving rise to inadequate transportation.

In the present study group, $14 \%$ of patients had history of previous abortion which is close to the study done by Khaleeque F, et al. ${ }^{16}$ (12.9\%). The relationship between prior abortions and ectopic pregnancy is explained by the post-abortal infections leading to tubal damage. In the past, these post-abortal infections were due to illegal abortions which were not done under aseptic precautions and lack of proper antibiotic coverage.

In our study group, $10 \%$ of the women with ectopic pregnancy were infertile which is correlating with the studies done by Panchal D, et al. ${ }^{11}(11.66 \%)$ and Samiya Mufti, et al. ${ }^{10}(8.77 \%)$. The association between infertility, previous pelvic infection and tubal pathology is the possible explanation.

In our study group, $14 \%$ of the women had history of previous ectopic pregnancy which is correlating with the studies done by Samiya Mufti, et al. ${ }^{10}(5.26 \%)$ and Uzma Shabab, et al. ${ }^{17}(5 \%)$. There is increased risk of ectopic with previous ectopic pregnancy because it reflects the underlying tubal pathology which is almost always bilateral.

In our study group, $14 \%$ of the women with ectopic pregnancy had tubal sterilization which correlates with the studies done by Uzma Shabab, et al. ${ }^{17}(5 \%)$ and Shrestha, et al. ${ }^{18}(5 \%)$. Improper surgical technique and formation of peritubal fistulas may result in ectopic pregnancy. In postpartum period, edematous, congested and friable tube increases the chance of incomplete tubal occlusion resulting in ectopic implantation.

\section{Conclusion}

The rise in the incidence of ectopic pregnancy is going in parallel with the rise in the incidence of risk factors like sexually transmitted infections, increased tubal sterilization and reversal, delayed child bearing, assisted reproductive technology, increased awareness and improvements in diagnostic techniques available. Despite many advances in the diagnostic techniques, ectopic pregnancy is still a diagnostic dilemma because of its varied clinical presentation. Increasing awareness among sexually active women and men regarding safe sexual practices and contraception decrease abortions and reduces the risk of ectopic pregnancy. All high risk women should be screened at the earliest with serum $\beta$ hCG and transvaginal sonography. The impact on future fertility can be improved by focusing on primary prevention and early diagnosis before rupture.

\section{Conflict of interest: None. Disclaimer: Nil.}

\section{References}

1.Te Linde RW, Rock. Telinde's Operative Gynaecology. 8th ed. Philadelphia: Lippincott - Raven; 1997. p. 501-27.

2.Centre for Disease Control and Prevention. Ectopic Pregnancy - United States, 1990-92. MMWR Morb Mortal Wkly Rep. 1995 Jan 27; 44(3): 46-8.

3.Rajkhowa M, Glass MR, Rutherford AJ, Balen AH, Sharma V, Cuckle HS. Trends in the incidence of ectopic pregnancy in England and Wales from 1966-1996. Br J Obstet Gynaecol. 2000 March; 107: 369-74.

4.Department of Health. Why mothers die : a confidential enquiry into the maternal deaths in the United Kingdom. In Drife J, Lewis G (eds): Norwich, UK : HMSO. 2001; 282. 
5.Stovall TG, Ling FW, Buster JE. Outpatient chemotherapy of unrup tured ectopic pregnancies. Fertil Steril. 1989; 51: 435.

6.Stovall TG, Ling FW, Gray LA, Carson SA, Buster JE. Methotrexate treatment of unruptured ectopic pregnancies: a report of 100 cases. Obstet Gynaecol. 1991; 77:749.

7.Sultana CJ, Easley K, Collins RL. Outcome of laparoscopic vs tradi-tional surgeries for ectopic pregnancies. Fertil Steril. 1992; 57: 285.

8.Delacruz A, Cumming DC. The factors which determine the fertility after a conservative or radical surgical treatment for ectopic pregnan $\neg$ cy. Fertil Steril. 1997; 68 :871.

9.Musa J, Daru PH, Mutihir JT, Ujah IA. Ectopic pregnancy in Jos Northern Nigeria: prevalence and impact on subsequent fertility. Niger J Med. 2009; 18: 35-8.

10.Samiya M, Shagufta R, Samina M, Reyaz A R, Wasiqa K. Ectopic pregnancy: An analysis of 114 cases. JKPractitioner. 2012; 17(4): 20-3.

11.Panchal D, Vaishnav G, Solanki K. Study of Management in Patient with Ectopic Pregnancy. National Journal of Integrated Research in Medicine. 2011; 2(3): 91-4.

12.Rashmi A Gaddagi, AP Chandrashekhar. A Clinical Study of Ectopic Pregnancy. Journal of Clinical and Diagnostic Research. 2012; 6: 867-69.

13.Poonam Y, Uprety D, Banerjee B. Ectopic Pregnancy two years review from BPKIHS, Nepal. Kathmandu Uni Med J. 2005; 3: 365-9
14.Shetty S, Shetty A. A clinical Study of Ectopic Pregnancies in a Tertiary care hospital of Mangalore, India. Innovative Journal of Medical and Health Science. 2014; 4(1): 305-9.

15.Bhavna, Gupta K.B, Pathania K, Jindal M, Vohra R, Ahmed M. Risk Factors For Ectopic Pregnancy: A Case Control Study In Tertiary Care Centre. Journal of Dental and Medical Sciences. 2014; 13(3): 23-27.

16.Khaleeque F, Siddiqui RI, Jafarey SN. Ectopic pregnancies: A Three year study. J Pak Med Assoc., 2001; 51:240-43.

17.Shabab U, Hashmi HA. Different pattern of presentation of ectopic pregnancy and its management. Journal of Surgery Pakistan (International). 2013; 18: 1.

18.Shrestha J, Saha R. Comparison of laparoscopy and laparotomy in the surgical management of ectopic pregnancy. J Coll Physicians Surg Pak. 2012; 22: 760-64.

19.Konar H, editor. DC Dutta's Textbook of Obstetrics. 7 th ed. New Delhi: Jaypee Medical Publishers; 2013. p. 177-89.

\section{Nethra HS ${ }^{1}$, Praneetha $\mathrm{K}^{2}$, Sreelatha $\mathrm{S}^{3}$, Seema Shyam Bhairi ${ }^{4}$}

${ }^{1}$ Junior Resident, ${ }^{2}$ Junior Resident, ${ }^{3}$ Professor, 4Junior Resident, Department of Obstetrics and Gynaecology, ESIMC, PGIMSR, Rajaji Nagar, Bangalore, India 